\title{
Response to letter by Dr. Fathi and colleagues
}

\author{
Deepti Bhargava $\cdot$ Paul Chumas
}

Received: 29 October 2009 / Accepted: 31 October 2009 /Published online: 21 November 2009

(C) Springer-Verlag 2009

\section{Dear Sir,}

We thank Dr. Fathi and colleagues for their interest and comments on our paper.

There are several alternatives for skull reconstruction, and each of them have their indications, benefits and limitations with the onus of responsibility being on the surgeon to decide what best applies to a specific case scenario.

Our paper describes an alternative technique for manufacture of titanium cranioplasty plates. We acknowledge, as in the original paper, that limitation of this technique is that an intact bony template is needed, and hence, this technique may only be used for delayed reconstruction in cases where intact bone is available, hence making it unsuitable for open skull fractures, bone flap tumour invasion and calcified hematomas, etc. In these cases, PMMA reconstruction recommended by Dr. Fathi is currently used in our centre as well.

However, with aggressive management of head injury and malignant stroke, decompressive craniectomy has evolved as the major indication for cranioplasty. For these cases needing delayed reconstruction, titanium offers certain advantages above other materials [references 1, 6, 7, 13, 18, and 22 in original paper (1)], hence, the role for our technique.

\section{Reference}

1. Bhargava D, Bartlett P, Russell J, Liddington M, Tyagi A, Chumas P (2009) Construction of titanium cranioplasty plate using craniectomy bone flap as template. Acta Neurochir, 16 Jun 2009 (online) 